\section{Human health risk assessment (HHRA) of arsenic and mercury from large- and artisanal-scale gold mining districts of Senegal (West Africa)}

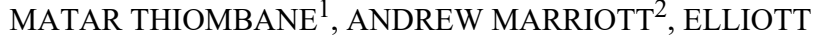 \\ HAMILTON $^{2}$, MICHAEL WATTS ${ }^{2}$, BIRANE NIANE ${ }^{3}$ AND \\ MARCELLO DI BONITO \\ ${ }^{1}$ Ram-Ses srl Parc scientifique CREALYS \\ ${ }^{2}$ British Geological Survey \\ ${ }^{3}$ Ministère des Mines et de la Géologie \\ ${ }^{4}$ Nottingham Trent University \\ Presenting Author: marcello.dibonito@ntu.ac.uk
}

Gold $(\mathrm{Au})$ mining activities at large or artisanal /small scale (LSGM and ASGM) mines can cause significant ecological and human health impacts, which are poorly evaluated. This study aims to consider the risks associated with two potentially harmful elements (PHE), arsenic (As) and mercury (Hg). The study considered concentrations in soils, sediments and fish samples, to define the potential health risk on children and adults exposed to both geogenic materials and contaminated food sources. The investigation took place in the Kedougou region of Senegal, West Africa, where gold mining activities are an important source of livelihood for the local communities.

A total of 76 topsoil samples $(0-20 \mathrm{~cm}), 45$ stream sediments and 25 fish samples were collected over an area of $6,742 \mathrm{~km}^{2}$. Fish were collected along sections of the Gambia River near villages where ASGM is taking place. Samples were analysed by ICP-AES and ICP-MS for 'pseudo-total' concentrations. A frequency space-method and regression model were applied to investigate sources of PHEs. Results showed both $\mathrm{As}$ and $\mathrm{Hg}$ anomalies in soils and sediments are strongly correlated to LSGM and ASGM. Moreover, Hg had bioaccumulated in fish samples, with mean concentrations generally exceeding legal threshold limits $(0.5 \mathrm{mg} / \mathrm{kg})$ for fish products in Senegal (Table 1).

HHRA based on 95\% UCL concentration of As and $\mathrm{Hg}$ in soils showed no non-carcinogenic risk for children and adults (Hazard Index, $\mathrm{HI}<1$ ), with vapor inhalation and soils ingestion being the major exposure pathways for $\mathrm{Hg}$ and $\mathrm{As}$, respectively. The distribution of Hazard Quotient (HQ) for soils ingestion exposure for children and adults was mapped in detail for the Kedougou area (Fig. 1).

Health risk estimation, based on fish consumption calculated by estimation of daily intake (EDI) and target hazard quotient (THQ, non-carcinogenic health risk), showed possible adverse human health effects for children and adults if consuming fish either daily or a weekly basis. This investigation provides an initial HHRA for the Kedougou communities associated with ASGM, advocating the establishment of stronger guidelines and institutional responses for a more adequate and comprehensive regulation of gold mining activities in Senegal.
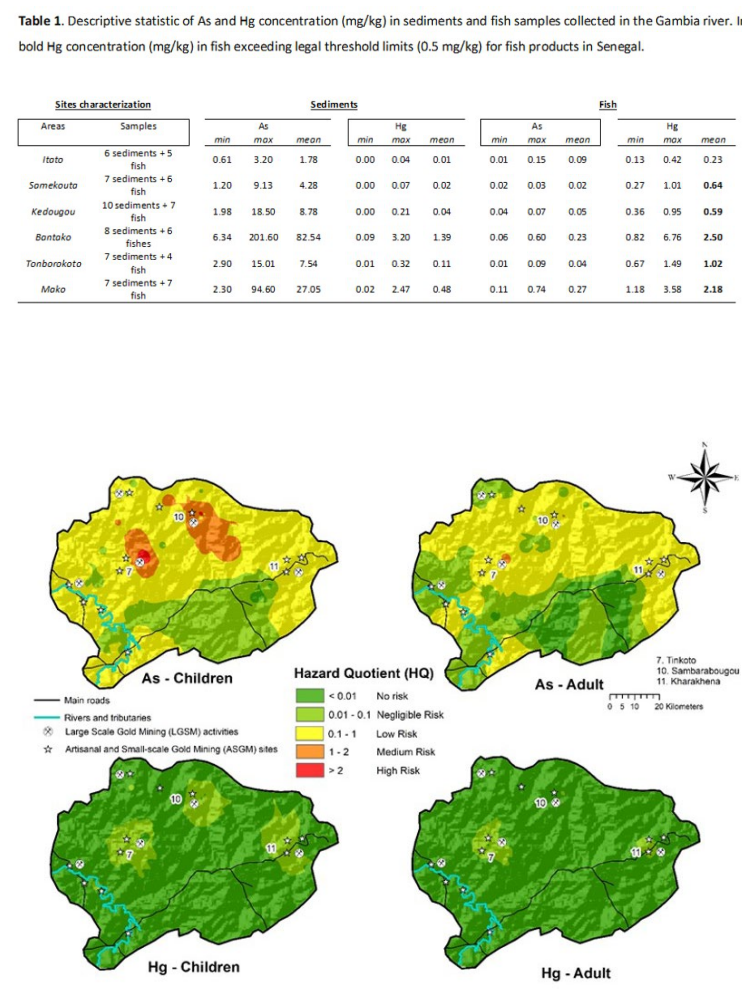

Figure 1. Spatial distribution of Hazard Quotient (HQ) of As and Hgexposure through soil ingestion for children and adults. 